\title{
FRAMING ENVIRONMENTAL PROBLEMS: PROBLEM ENTREPRENEURS AND \\ THE ISSUE OF WATER POLLUTION FROM AGRICULTURE IN BRITTANY, 1970-2005
}

\author{
Magalie Bourblanc $c^{\text {ab }}$ \\ a CIRAD, UMR G-EAU, F-34398 Montpellier, France \\ $\mathrm{b}$ Department of Agricultural Economics, CEEPA, University of Pretoria, Pretoria, South Africa
}

\begin{abstract}
The claim that public problems are constructs is now widely recognized as justified and was first established in social problem theory. The high instability of problem definition activities in the case of water pollution coming from agriculture in Brittany demonstrates this particularly well. The objective of this article is to describe ways by which an environmental movement organization (EMO) conceives its activities of public problem construction. Inspired by social movement theory, but aiming at overcoming its weaknesses, the paper seeks to highlight the influence of EMO endogenous meaning production in problem construction processes, a dimension often overlooked even by framing theory. In a bid to support that claim, the paper shows the influence of the affective dimension over the strategic one within the problematization process. Forging a conceptual distinction characterized by a perceived problem and strategic definitions, the paper underlines the fundamental interrelated nature of these two components and consequently emphasizes the reciprocal dependence of the perceived problem over the strategic (either material or cognitive) definitions. Finally, the paper evokes the benefit and impact of this conceptual distinction on the policy-making process.
\end{abstract}

\section{Introduction}

Since the 1970s, Brittany has been renowned for its ongoing problem of non-point source pollution coming from agriculture. Although Brittany is not the only region in France concerned by this type of pollution, since areas in central, west central and north eastern France are also affected, for almost 30 years the problem was only associated with this particular geographic area. Some problems can indeed be "orphans", meaning they cannot emerge in the public sphere despite their "objective" existence. As Kitsuse and Spector (1973, p.415) put it:

"the existence of social problems depends on the continued existence of groups or agencies that define some condition as a problem and attempt to do something about it. To ask what are the effective causes of social problems, or what keeps social problems activities going, is to ask what keeps these various groups going".

Social problem theory analyzed the processes of problem objectivation and (re)definition quite early on (Baumgartner \& Jones, 2002; Cobb \& Elder, 1983; Kitsuse \& Spector, 1977). These authors considered that social problems were not simply research data but were the product of a social mobilization. For many years on the contrary, public policy 
analysis considered public problems to be 'taken for granted' (Vlassopoulou \& Larrue, 1999) until seminal works in the field opened the black box (Kingdon, 1984; Padioleau, 1982). Since then, public problems have been treated as mobilization constructs. This statement does not confine itself to social problems. In spite of their link with natural phenomena, environmental problems are far from conveying a universal definition that imposes itself more or less automatically. According to Yearley (1991), the existence of objective circumstances that are worth formulating as a problem is not sufficient to ensure the emergence of this problem for society.

A striking phenomenon in the case of water pollution coming from agriculture in Brittany is the high instability of the definition(s) of the problem. Although in a longitudinal study of public policies, Rochefort and Cobb (1994) already stated that problem redefinition is more often the rule than the exception, the renewal rate of problem definition is an intriguing issue, especially when it concerns the same social movement organization (SMO). The objective of this article is thus to focus on how SMOs construct a problem and on why they construct the problem the way they do. In particular, we will relate these ways of constructing the problem to the policy-making process.

Two bodies of literature can be mobilized for that matter: traditional social problem theory extended into public policy analysis literature on the one hand and social movement theory on the other hand. They emphasize rather similar dimensions. Firstly, traditional social problem theory and public policy analysis both concentrate on modalities for extending advocacy. Because of its focus on public actors and actions, public policy analysis concentrates more on contextual and exogenous variables than does social problem theory, which is more interested in the SMO that raises the issue, the SMO being the starting point from which the construction of a public problem is considered. Nevertheless, both schools 
share a tendency to emphasize the rational or strategist aspect of problem definition activities. For instance, Kingdon (1984) refers to actors' resources and opportunities, while Edelman (1964) refers to the strategic use of language and symbols.

Secondly, in the realm of social movement theory, resource mobilization theory (RMT) touched on both exogenous and endogenous factors of social movements (Oberschall, 1973). However it did so while focusing only on material dimensions. In reaction to this problem, framing theory (Benford \& Snow, 2000) promoted the role of ideas and meaning production in social movements. Nevertheless, because of the influence of RMT in the literature on social movements, frame analysis has itself been accused of placing too much emphasis on instrumental frames and of neglecting the more affective dimension of meaning that exists within a group (Benford, 1997). Hence, it seems that the more internal aspects of the cognitive dimension is very often neglected (configuration 1 in Table 1 , see below).

(Table 1)

We argue that the affective dimension linked to endogenous aspects of SMOs (configuration 1) is also a critical factor in problem definition activities. Another way to put it is to say that, apart from distinguishing the material vs. cognitive dimensions or the endogenous vs. exogenous ones, another criterion could concentrate on the extent to which a strategist/rationalist or on the contrary a more affective dimension do shed light on problem construction activities. To remedy this literature gap, we identified both endogenous and exogenous, cognitive and material dimensions as relevant dimensions to take into account in public problem construction. Most importantly, we pay attention to both strategist and affective dimensions and recombine all these dimensions in a conceptual distinction: the 
Table 1. The four dimensions of public problem construction

\begin{tabular}{lcc}
\hline & $\begin{array}{c}\text { Endogenous dimension } \\
\text { (internal to SMO) }\end{array}$ & $\begin{array}{c}\text { Exogenous dimension } \\
\text { (external to SMO) }\end{array}$ \\
\hline Cognitive dimension & $\begin{array}{c}\text { Configuration 1 } \\
\text { Affective dimension } \\
\text { (values; beliefs; emotions) }\end{array}$ & $\begin{array}{c}\text { Configuration 2 } \\
\text { Cultural and societal frames }\end{array}$ \\
& $\begin{array}{c}\text { Configuration 3 } \\
\text { Organizational resources }\end{array}$ & $\begin{array}{c}\text { Configuration 4 } \\
\text { Political structures and opportunities; } \\
\text { political context }\end{array}$ \\
\hline
\end{tabular}


affective dimension or "perceived problem" (Configuration 1) and the "strategic problem definition(s)" (Configuration 2;3;4). The strategic problem definitions can refer to instrumental frames, to the use of political opportunities structures or of organizational resources. These strategic definitions are designed for the purpose of extending the cause beyond the initial group's concerns. The perceived problem corresponds to the problem internalized by the SMO, i.e. the problem that prompted SMOs to engage in collective action in the first place. Eventually, our aim is to account for the contribution of SMOs to the dynamic and interactive process of public problem construction -or problematization process-.

The importance of studying public problem construction process in policy-making is now well documented (Gilbert and Henry, 2009). It even motivated the shift in public policy analysis from a classical analysis of "public policies" to a "political sociology of public action" (Lascoumes and Le Galès, 2006). "Public action" rather than "public policies" focuses not exclusively on public actors but extends its analysis to non-state actors and social movements (Thoenig, 1998). In that respect, public action is said to result from the "collective making of actors in interaction" (Hassenteufel, 2008). Paying a particular attention to public problems' construction, the study of public action underlines that this construction is never done once and for all but stretches over the entire policy-making process. The impact of problem definition on policy-making process has already been highlighted concerning a close collaborator of agricultural administration, i.e. the majority farmers' union (Bourblanc \& Brives, 2009). The work shows how the strategic framing of agricultural pollution in terms of non-point source pollution has had major consequences on policy instruments' choice and on the path followed by public policy in general. The objective is now to focus on the environmental social movement which here appears as a policy outsider. Considering the importance of the problematization for policy-making process, our research question will thus 
concentrates on how such a social movement constructs a public problem in order to put it on the agenda and on the reasons why it constructs the problem the way it does.

Indeed, it is important to emphasize that reflecting on policy-making processes through the study of problematization will be done by adopting a social movement organization's perspective. In that respect, our aim is not to discuss what explains the success or failure of any particular attempt to place an issue on the public agenda. Such a question is beyond the scope of this paper and would require adopting the perspective of public actors, not only SMO's one. Nor is it our aim to suggest what characteristics of a problem make it a good candidate for the media agenda. We will not be able to make a comprehensive contribution to the literature on public problem emergence or on the agenda-setting process within public policy analysis (Cobb \& Elder, 1983; Rochefort \& Cobb, 1994). In other words, instead of accounting for the activities of "policy entrepreneurs" (Kingdon, 1984), we will be discussing the work of "problem entrepreneurs" more specifically. According to Kingdon, policy entrepreneurs are concerned with three streams (i.e the problem stream, the policy stream and the politics stream) that they actively try to bring together in order to create a window of opportunity. Thus, policy entrepreneurs get involved in a broader range of policy formation activities as compared to problem entrepreneurs mainly dealing with the agenda-setting process. In addition, without denying the role of different interest groups or public actors in shaping the problem definition strategy of one specific problem entrepreneur (Lascoumes \& Le Galès, 2006), it will not be possible to directly evoke their influence within the space limit of this article. Therefore, some of these different groups will only appear implicitly as our account will stay focused on one SMO in particular.

By exploring the modalities through which a SMO in particular constructs its cause as a potential public problem, we apply the conceptual distinction discussed above to the empirical 
material collected in a $\mathrm{PhD}$ thesis in public policy analysis. This $\mathrm{PhD}$ thesis focuses on public programs dealing with agricultural pollution of water resources in Brittany and NoordBrabant (Netherlands) from 1970 to 2007 . For the French part, the study included 100 semistructured interviews (with local and national environmental organizations, politicians, civil servants, consumers NGOs, farmers unions, agricultural organizations); an analysis of the national and regional press media over a 5-year period; and an analysis of policy documents and regulation. More specifically regarding ERB, the study included 10 semi-structured interviews with ERB members and staff, analysis of the organization's website and journals over a 30-year period and, more broadly, observations of the commitment of the organization in the above mentioned water policies.

In this article, we first show the rather stable definition of the perceived problem in contrast with the rapidly evolving strategic definitions that we illustrate next. However in another section, we demonstrate that these opportunistic strategic definitions are limited to a particular range of definitions, meaning that not all possible definitions are explored. In line with this idea, we give an illustration of the existence of an inter-dependence between the perceived problem and its strategic definitions. We particularly emphasize how the design of strategic definitions is influenced by SMO leaders' affective motivations. Thus, instead of trying to be exhaustive, we highlight certain episodes of this definitional process rather than others in a bid to illustrate the relation of mutual dependency that links these two dimensions of problematization. Finally, we discuss the contribution such a conceptual distinction between a perceived problem and strategic definitions can make to a better understanding of the policy-making process, and notably how useful it can be for anticipating on future development of the policy-making process. 


\section{The Perceived Problem for Eau et Rivières de Bretagne}

Despite being a rather small environmental organization, Eau et Rivières de Bretagne, ERB (Water and Rivers of Brittany) is a well-known environmental NGO whose name is associated with the water quality struggle in France. ERB is the second biggest environmental NGO in Brittany, one of 22 French regions. ERB is a federation that gathers 72 local environmental organizations and around 1000 independent members (Rapport moral d'Eau et Rivières de Bretagne, 2008). When it was founded in 1969, it was mainly composed of a small number of recreational fishermen who wanted to solve the problem of decreasing salmon intakes in rivers in Brittany. Some of its founders were members of a conservancy association, from which they subsequently split. Until the mid-1970s, ERB was interested in all topics related to river fishing, halieutic tourism and fishermen's rights, denouncing problems with fish farms or with the practices of certain fishermen.

Concerning its action repertoire, ERB very rapidly favored educational actions targeting the general public. With this aim in view, in the 1970s and 1980s, ERB organized several river clearing actions to remove all potential obstacles to the migration of salmon in the rivers and thus prevent their death. The clearing actions were popular events sometimes gathering up to 1000 people. The events also responded to the major "land consolidation" operations of the 1970 and 1980s which aimed at extending cultivatable land to facilitate the use of modern agricultural machinery. In particular, extending arable land was intended to encourage farmers to grow crops like maize, which in Brittany are very much associated with intensive breeding since, among other uses, maize is used as feed in intensive pig farms. 
For ERB volunteers, clearing rivers provided the opportunity to discover another side of what was then referred to as "Brittany's economic miracle" (Le Bourdonnec, 1996), i.e. the rapid development of modernized agriculture: volunteers had to clear the river of tree stumps carelessly dumped in the watercourses after rural engineering works. Those who took part in clearing rivers were very sensitive to the rapid transformation of the local rural landscapes: hedges and embankments ("bocage" in French) were sacrificed by the agricultural administration for the sake of bigger fields.

During these river clearing activities, intensive agriculture became ERB's main "target". For ERB, intensive agriculture was responsible not only for the depletion of salmonid resources but also for the loss of the aesthetic environment in which fishing can be practiced as a leisure activity. As one local ERB leader vehemently put it during an interview conducted in March 2004:

"When rural engineering machines started erasing the embankments, it drove me crazy. I perfectly understand that some people could have bombed some of the administration bulldozers. They destroyed kilometers of hedges in our district." [the translation is ours]

From then on, intensive agriculture was the subject of a moral battle that denounced intensive breeding for being, in ERB's opinion, nothing more than an industrial activity. Although not often openly expressed, this perception is striking when compared to perceptions in the Netherlands where there were also protests against pollution caused by intensive agriculture. Indeed, the comparison made it obvious that ERB ideologically opposed the new Breton agricultural model per se, and not only its environmental consequences. To put it bluntly, we could claim that ERB more specifically supported an agricultural (counter-) project based on small-scale farming rather than an ecological project. As a local environmental association leader put it in an interview conducted in December 2002: 
"we need farmers in our countryside. Contrarily to what they think we are not against agriculture, we are just against this kind of extremist agriculture [...] We will not solve the problem by processing nitrates. We are in favour of sustainable solutions, we want people in our countryside, we want farms to preserve our landscapes, that is our goal [...] We are in favour of a new agricultural model" [the translation is ours]

In that respect, ERB's "policy core belief” (Jenkins-Smith \& Sabatier, 1994) is very close to that of the opposition farmers' union La Confédération Paysanne, whose agricultural project is also based on a sustainable small-scale farming model that supports a high number of farmers in the countryside against farms' concentration as in the intensive agriculture model. As one of this farmers' union leaders put it in an interview conducted in January 2002:

"We and ERB have the same discourse I think. On the long run, we both share the objective of the progressive reduction of herd size and the return to small-scale agriculture linked to land availability" [ the translation is ours]

The proximity between the two organizations is occasionally on display during demonstrations against agricultural pollution.

The conclusions we have drawn concerning the "real" problem for the ERB were deduced from the specific associative experience and trajectories of only a few members of ERB. It by no means covers the broader range of opinions this regional federation of local environmental NGOs represents. For that reason, our statement about the perceived problem may appear reductionist in the sense that it is only based on the study of ERB leaders and not on the full range of its members. By leaders, we mean the founding fathers and the historical staff of the organization. This is a voluntary choice based on the postulate that despite the democratic organization of ERB, its decisions and politics are oriented by only a few active long-term militant members. 
Criticizing the modernization and intensification of agriculture was not appropriate in a period (1970s and 1980s) during which the legitimacy of "Brittany's agricultural model" reached its peak. Up to the 1950s, Brittany was characterized by its geographic and cultural isolation in the far west of France. Brittany also differed from other French regions with regard to the poor living standards of its population. "Brittany's economic miracle" is said to have put an end to the massive exodus of young people from the region and to have contributed to making the region and the countryside "alive", thanks to the construction of transport infrastructure, and stopping it from becoming a "desert" by connecting a lot of small towns. In regional accounts, farmers and the network of agro-businessmen around them are depicted as capitalist leaders who worked not for their own profit but for the benefit of the region and its population, whom they rescued from poverty and underdevelopment (Le Bourdonnec, 1996).

Thus, instead of vainly protesting against the promoters of this model within society, which was widely considered to be legitimate, ERB sought a more convincing way to pursue its target as we will see in the following sections. Intensive agriculture was never openly put on trial, at least not directly. Although in ERB's opinion, intensive agriculture is the real problem, the organization never declared this openly in its strategic definition of the problem. The problem of intensive agriculture (perceived problem) was introduced only as a logical deduction of a more legitimate public problem (strategic definition). Even though common sense would dictate that ERB was primarily trying to alert public opinion about an undesirable situation (pollution of water courses), and only secondarily trying to identify those responsible for it, without any pre-conceived ideas about the situation or about possible remedies, in reality things were quite different. We find a confirmation of this phenomenon (i.e. having a target in mind before tailoring one's problem as a legitimate stake) in the fact that a strategic definition is generally extremely volatile in contrast to the more stable identity 
of the actor who is accused of being responsible (perceived problem). This is perfectly revealed by the interview conducted in March 2004 with an ERB local leader:

"Should we have framed things in terms of public health or in terms of environmental problems as we did? [...] In retrospect, I think we should have opted for public health issues. In that case it is simple, let us ask for the banning of antibiotics, then there will not be industrial husbandries any more, it will be over, farmers can not engage in industrial poultry or pig farming without antibiotics. We should have revised our strategy in that sense" [the translation is ours]

We will depict this rapid evolution of strategic definitions in more details in the following sections.

\section{Mobilizing Available Resources in the Strategic Construction of Problems}

Faced with the inefficiency of their previous attempts to put intensive agriculture problems on the public agenda, in the mid-1980s, ERB decided to radicalize its actions. In the past, if pedagogical means and persuasion had been used to create a social movement around rivers, from then on juridical weapons were used that targeted major representatives of the majority farmers' union or representatives of cooperative agro-industries. In a strategy aimed at discrediting symbolic figures of productivist agriculture, they decided to exploit information leaks about practices widely used in intensive pig farming, i.e. the extension of pig breeding activities without administrative authorization. First ERB confronted the main entrepreneurs of "Brittany's agricultural model" in the administrative courts. Highly publicized successes against emblematic figures of productivist agriculture in the mid-1980s helped undermine the image of these personalities among the general public in Brittany. Then, starting in 1993, criminal charges were brought against leaders of intensive agriculture (Bourblanc, 2007). 
Although smaller scale farms were also concerned with these illegal practices, they were never targeted as one ERB former board member put it in an interview in February 2003:

"we would not sue smaller size farmers because we are not against agriculture. We only wanted to undermine the reputation of bigger representatives of intensive farming. Our juridical actions were symbolic actions" [the translation is ours]

This juridical strategy produced the expected result: the Department of Agriculture, which had close links with the promoters of intensive agriculture, was forced to react. In 1993 the Department drew up its first program, PMPOA (Programme de Maîtrise des Pollutions d'Origine Agricole), to deal with pollution caused by agriculture. However, this public response and the content of PMPOA did not satisfy ERB, mainly because it did not challenge the intensive mode of production. New strategic arguments were used to prolong the life of its cause despite the existence of the PMPOA.

In that context, a piece of European legislation provided a good opportunity for ERB to keep its problem on the agenda. Since 1975, a European directive has regulated the use of drinking water from surface water courses in which nitrates exceed $50 \mathrm{mg} / \mathrm{l}$ (75/440/EEC June 16, 1975). The focus on nitrates thus offered an advantage. Until the early 1990s, French legislation allowed up to $100 \mathrm{mg}$ of nitrates per liter. In her study of the ERB journal, Mettoux (2002) reported a thematic shift at the beginning of the 1980s, when nitrates and its impact on human health started to appear more and more frequently in its columns. Again ERB chose a juridical battle to try to force the French administration to transpose the European legislation into French law, a process that took more than 15 years to succeed (Bodiguel, 1996). Then, in 1992, ERB appealed to European Union authorities to have France's failure to implement binding European legislation condemned. The French government was convicted in 2001 and again in 2007, resulting in major pressure from the European Union to implement substantial changes in agricultural practices in Brittany. 
Compared to the issue of pesticides, it is clear how much strategic problem definition depends not only on existing opportunities but also on constraints on the seizing of opportunities. This idea is already expressed in RMT, which relates it to the internal organizational capacity of a social movement. However here we would like to focus on constraints concerning the perceived problem and preconceived solutions to the problem at stake. Therefore, even though surface water courses in Brittany have undergone contamination way beyond legal limits (see «DIREN Bretagne » report, 2000), pesticides have not been a priority argument for ERB in its struggle against non-point source pollution coming from agriculture, although it could appear as a strategic leverage. Indeed, public opinion expressed considerable concern regarding the toxicity of herbicides and pesticides. Part of the explanation is the fact that unlike nitrate pollution, the technology needed to detect pesticides in water was not easily accessible. The concentrations of pesticides and herbicides in water only started to be systematically analyzed in the mid-1990s. However a more likely explanation concerns the constraints imposed by the perceived problem on the strategic definition of the issue on the agenda. The impact of pesticides and herbicides on human health is so alarming that all stakeholders generally agree on emergency remedial solutions to tackle the problem, whereas the impact of high rates of nitrates on human health is more controversial, as we will see later on.

Against this background, ERB secretary made it clear in an interview in June 2002 that ERB could accept treatment as a solution for pesticide-free water destined for human consumption -even though it would rather encourage preventive measures in this case too- but would strongly oppose the same remedial treatment to remove nitrates from drinking water. ERB disapproved of any remedial solution to the nitrates issue and instead encouraged preventive solutions since, again, nitrates is not the main concern of the organization, but rather a strategic way to fight intensive agriculture. 
A strategic definition in terms of nitrates represented a good potential for ERB because of the direct link that could be made with intensive agricultural practices after the publication of a scientific report, the "Hénin report", commissioned in 1980 by the National Committee on Water (a consultative governmental body). Regarding pesticides and herbicides, the unique responsibility of intensive agriculture is more difficult to establish since many recreational and municipal gardeners also use a lot of these products. In addition, blaming what could be perceived as an "industrial" type of agriculture for the use of pesticides and herbicides was not so easy, because the size of the farm has little to do with the means to combat over-use of plant protection products. Conversely, the Hénin report made it very clear that the increase in the rate of nitrates in rivers was attributable to the overflow of manure on farmlands and its runoff to the rivers. In this particular case, the size of the herd and of the farm were more directly incriminated since such overflow is due to a misbalance between the volume of animal waste and the availability of land on which it can be spread. In the following section, we provide another striking example of the constraints the perceived problem can impose on strategic problem constructions.

\section{Constraints of the Perceived Problem on Strategic Definitions}

Establishing that the perceived problem can impose some constraints on strategic definitions helps understand the lack of enthusiasm with which ERB viewed the interference of other environmental NGOs in the problematization process. Some authors call this phenomenon "problem ownership" (Gusfield, 1980; Stone, 1989), underlining the interest that an organization has in controlling a problem in order to maintain its position as a legitimate partner in the decision-making process. We would like to emphasize a more ideological 
component in this behavior, arguing that it is not only a question of securing the involvement of the organization for its own sake (irrespective of the definition of the problem) but more specifically securing a particular problem definition.

Although we have stated that the perceived problem and the strategic definition were two distinct sides of the problematization process, it is clear that they are inter-connected. One example illustrates this point, showing how pro-active the perceived problem can be in the selection of appropriate opportunities and resources (strategic definition). This example refers to the mobilization of the "collectif eau pure" ("Pure Water Association") in the boycott of paying water bills. The Collectif Eau Pure (CEP) was composed of many local NGOs but principally led by FAPEN, a federation of about 50 local environmental NGOs in the Côtesd'Armor district in Brittany, which is also a member of ERB. According to an interview with CEP's former spokesman in February 2003, CEP complained about receiving little support from ERB in the mid-1990s when it started its call to boycott the payment of water bills in a few towns in Brittany. The idea was to protest against nitrate contents that exceeded the legal limits in drinking water.

The mobilization was successful and several cases brought against municipalities and water delivery services were won, but the work involved was time consuming and exceeded the organizational capacity of the CEP, which is not an institutionalized movement but just a temporary coalition. However, the aim of the organizers was to expand the boycott to the whole region, but to achieve this, they needed more established environmental NGOs to take over. If ERB publicly supported CEP's actions, sometimes even demonstrating alongside them, like in Lannilis in 2003, ERB refused to actually invest in this social movement. According to interviews conducted in December 2002 with FAPEN's chairperson and treasurer, this created a lot of tension between ERB and the FAPEN/CEP, the latter 
denouncing the new collusion between ERB and the public administration, and the new status of ERB as a partner of the establishment and no longer a challenger of State policy. To anyone who is aware of the dual nature of ERB's repertoire of actions, which alternate between conciliation with public authorities and protest actions against the same authorities, this does not seem a likely explanation. A more satisfactory explanation for the reluctance of ERB to engage in the boycott to pay water bills may be the limits imposed by the perceived problem on the strategic definition.

Indeed, even though CEP's action is concerned with the high rate of nitrates, like ERB, it mainly concentrates on nitrates in drinking water, not in water resources, the latter being ERB's main interest. This detail changes not only the problem at stake -human health issues for CEP and a more environmental issue for ERB- but also the target. With the CEP boycott, the Department of Agriculture and leaders of intensive agriculture escaped blame and criticisms were addressed more directly to water service authorities, either municipalities or private companies on behalf of municipalities. However, municipal authorities were as much the victims of the high concentration of nitrates in rivers as were the water consumers themselves. Indeed, these political elites do not take part in agricultural policy arrangements in the region. This shift in target from the promoters of intensive farming to municipalities was problematic for ERB as its regional delegate admitted during an interview conducted in August 2007:

\footnotetext{
"You are asking me why ERB never thought about this boycott even though we were already committed to juridical actions. The answer is I don't know. It's true that at the time, ERB was quite reluctant, first because we are an environmental organization, not a consumer rights association. And also in our opinion there was another risk involved. We could see pretty much where this was going; there was a risk of encouraging the municipalities to secure everything in order to avoid a trial. They could have purchased more treatment plants to remove excess nitrates during the production process, and that was definitely not our objective. Our goal was protecting rivers and water quality from a
} 
resource perspective, but that was not what consumers' associations had in mind» [The translation is ours]

Indeed, one of the consequences of these trials was the installation of a nitrate treatment plant. Thus, not all strategic definitions can be envisaged, not only because of the internal material limitations of the organization (as in RMT) but also because of its internal cognitive constraints. Other types of pressure can also be exerted on the strategic definition process, this time from outside, depending on how the actors accused of being responsible for the problem, or others, react to problem entrepreneurs' definitions.

Indeed, obviously ERB's efforts to define a legitimate problem did not take place in a vacuum. First of all, identifying the "condition" as a problem prompted reactions from the accused themselves. Long before the qualification of the problem was debated, the very existence of a problem was denied (Cobb \& Ross, 1997). For the sake of space, we can not evoke all the controversies that were launched by ERB's opponents nor can we describe in detail the scientific controversy that prompted ERB to revisit its opposition to nitrates. This controversy is interesting however because it highlights the high reactivity of ERB's framing process, and the fact that once a strategic problem vanishes, it does not take the organization's cause with it. As a result of this controversy, nitrates had become an unsatisfactory ally in the strategic definition process, and ERB was forced to modify it; by the mid-2000s, the issue of phosphates and eutrophication causing green seaweed was pushed to the forefront by the organization. Interestingly, green seaweed started to increase on beaches in Brittany in the 1980s, but was only denounced by ERB in the 2000s. 


\section{Discussion: Benefit of the Conceptual Distinction}

Our initial question was to ask how and why ERB has been constructing its problem the way it has in the past. We have demonstrated that there was a method in the way ERB constructs a public problem. It is not only based on resources and opportunities used in a strategic way for public agenda-setting purpose, it is also driven by the group's perceptions of what the real problem is. Hence we used a conceptual distinction to account for these constraints on the problematization process, stating that for problem entrepreneurs, the problematization process is about responding to both affective and strategic (either cognitive or material) constraints and opportunities on the possible definitions of the problem. In our case, the "strategic definition" relates to the constraints on advocacy extension (external constraints), both horizontally concerning the prospects of extending the advocacy coalition and vertically concerning the prospects of generalizing the concern and of framing it in a way that pushes public authorities to deal with it (Boltanski, Darré \& Schlitz, 1984). However, the problematization process is also about constraints relating to the "perceived problem", i.e. the subjective representations that problem entrepreneurs project onto a specific issue and that correspond to a more endogenous and affective dimension of the issue at stake for problem entrepreneurs.

The mutual dependence of the two dimensions of problematization

Social Movement Theory literature has displayed several attempts to design a more syncretic approach in the sociology of collective action. We already criticized particular aspects of it 
but would like to build on other more positive ones as well as to overcome the identified weaknesses. As previously stated, resource mobilization theory has been widely criticized for paying too much attention to resources -either organizational or structural- in this respect following the rationalist paradigm in which it is embedded (Mc Carthy \& Zald, 1977). Indeed, although RMT posits itself as a critique of rational choice theory emphasizing the limits of its postulates, RMT only intends to remedy its shortcomings, not to challenge the rationalist paradigm (Neveu, 1996).

However, in the 1980s, new studies in the US underlined the fact that social movements do not depend as much on resources availability or political opportunities as on the way policy entrepreneurs interpret them and construct the meaning attached to particular situations. Seminal works in frame analysis illustrate this cognitive and symbolic turn in the conceptualization of social movements most successfully (Snow, Burke Rochford, Worden, \& Benford, 1986). McAdam, McCarthy and Zald's work (1996) demonstrates how influential framing theory became in the sociology of collective action. In the above-mentioned work, the initiators of RMT acknowledge the importance of three series of factors: structural or organizational resources, political opportunities, and framing processes. Building on this three-dimensional model, the "theory of political process" or PPT (Goodwin \& Jasper, 1999) rapidly became the new hegemonic paradigm in the social movements literature (Morris, 2004). Yet Contamin (2010) emphasizes how frames mainly appear as secondary factors or in a subordinate position in most versions of PPT. For most PPT authors, collective action is indeed triggered by material factors. In addition, even in the framing theory, the role of the cognitive dimension is still considered as rather instrumental in the construction of social movement as in Benford and Snow's "diagnostic" and "prognostic" frames (2000). Apart from this "strategist" bias, frame theory is also criticized for over-emphasizing the external 
constraint on the framing activity as in Steinberg (1999) "discursive fields" or Koopmans and Statham's "discursive opportunities" (1999).

We found the attempt at integrating different relevant variables within the PPT model inspiring and sought to overcome its weaknesses, i.e. the strategist bias, the over-emphasis on external influence and the subordinate position of frames. For that reason, our conceptual distinction provides a model of public problem construction that considers the cognitive dimension as both a principal variable and a variable articulated with the material dimensions. The cognitive dimension is a principal variable because as we have seen, perceptions of the problem do not necessarily act as mere filters of structural opportunities conceived as the principal factor for the emergence of a social movement. These resources or political structures do not always come first in explaining why a social movement emerges and the perceived problem is not doomed to be a secondary or mediating variable. In the case described here, perceptions not only affected which external resources were selected to ensure the claim had the most resonance; these perceptions actually triggered the social movement in the first place. In that respect, we demonstrated how much the internal cognitive dimension (or affective dimension) influences the strategist dimension. Indeed, the reluctance of ERB to fully commit to Collectif Eau Pure's boycott perfectly illustrates the constraints that the group's perceived problem can impose on promising resources for extended mobilization. Besides, the best evidence for the claim that perception comes first is the fact that apart from the circle of problem entrepreneurs, there were no external structural incentives for building a social movement around agricultural pollution of water sources in the 1970s in Brittany. It is precisely for this reason that more legitimate framings of the problem at stake were put forward over time, and that the real target of ERB was never declared upfront. 
The cognitive dimension is also an articulated variable. In that respect, we treated strategic resources and opportunities as important factors to be considered in our conceptual distinction. The diversity of problem definitions that is originally related to an illegal increase in the size of pig herds and more recently the green seaweed phenomenon, is an acknowledgement of the fact that without advocacy extension, i.e. without a strategic definition, the "perceived" problem is doomed to disappear because of the lack of prospects for the cause to exist outside the group that gave birth to it. Hence, the rapidity with which the strategic definitions evolved from nitrates to phosphates and eutrophication problems, points to the need for policy entrepreneurs to not stand still, but to rapidly react to counter-framing activities. Therefore, our objective has been to discuss interactions rather than one-way subordination of one dimension (either cognitive or material) to the other, and eventually to demonstrate the inter-dependency of the affective and strategic dimensions within the problematization process.

Yet, we do not claim that the problematization process (as conceived in the conceptual distinction) applies to all policy outsiders' attempts to get their cause on the public agenda. The idea that the perceived problem and strategic definition are distinct, even though interrelated, seems to be best suited for cases in which existing structural incentives (either ideational or material) discourage the emergence of social movements. Hence the need for further research to test and systematize this conceptual distinction in similar contexts where the perceived problem is at odds with surrounding societal and cultural paradigms, but also the need for a typology of situations where such a conceptual distinction could be applied; as well as the need for determining the specificity of environmental issues in such a problematization. Finally, we would like to evoke the impact of this problematization on the policy-making process. 
Contribution to the analysis of the policy-making process

Being able to make the difference between the "perceived" problem and opportunistic framings provides important advantages in the conduct of policy-making. If we take the example of phosphates, had the decision-makers been aware of this distinction and not fooled by the strategic definition publicized by ERB, they could have anticipated the next move by ERB. On the contrary, policy-makers fell short of an adequate response when ERB pushed the phosphate problem forward in the middle of the 2000s. ERB linked it to issues of soil erosion or green seaweeds that at the time had only attracted the attention of local seashore environmental associations with which ERB had only little contact. From an agronomic viewpoint, the link between phosphate surplus and eutrophication problems has been known for a long time. A balanced fertilization in terms of phosphate was even inscribed in the French law since the mid-1970s, although agricultural administrations were hardly ever implementing it, according to the ex-head of the Breton veterinary services interviewed in March 2004. Yet for policy-makers, ERB was fighting for rivers' improvement quality only. Reacting to nitrates problem, policy-makers compelled farmers to build processing plants which would solve nitrates surplus in rivers and only that. Farmers who had to invest in such expensive technologies were declared to be abiding by the law in the mid-2000s. When policy makers were forced to adopt new phosphate regulatory norms in 2006 , these farmers were no longer abiding by it. Embarrassed, agricultural civil servants had to explain to angry farmers that their brand new processing plants were already useless and no longer protecting them from infringement of pollution law. They had to invest in new technologies that would process both nitrates and phosphates surpluses (Bourblanc, 2013). 


\section{Conclusion}

This article highlights ways by which Eau et Rivières de Bretagne, an environmental NGO in Brittany (France), constructed the public problem of agricultural pollution of water resources. Rather than being exhaustive but focusing instead on certain critical moments in the definition process, we wanted to discuss the benefit of a conceptual distinction accounting for the problematization process in a particular context. This conceptual distinction allows us to understand both how ERB constructs their problem in order to put it on the public agenda and why public policy and policy solutions are encountering so many difficulties in solving the problem at stake. Eventually it can alert policy makers on the real problem at stake for problem entrepreneurs.

Indeed, we assumed that policy outsiders trying to get their issue on the public agenda will bear in mind two dimensions that constrain their problem definition, i.e. the perceived problem and the strategic definition. Analyzing the literature in social problem theory and social movement theory revealed the instrumentalist bias of these traditions as a more endogenous cognitive dimension is very often missing. Hence our emphasis on the affective dimension in public problem construction showing that social movement organization's affective motivations have a strong influence on their problem definition activities.

Moreover, we demonstrated that even though they are distinct, the perceived problem and the strategic definitions are very much inter-dependent. We did not want to only insist on the constraints that the affective dimension imposes on the strategic definitions. We also 
provided evidence of problem entrepreneurs' dependence upon a strategic definition on which they rely to ensure the very existence of their (perceived) problem on the public agenda.

\section{Acknowledgement}

I am very grateful to the two anonymous reviewers who commented on an earlier draft of this paper.

\section{References}

Apfelbaum, M. (2001). Nitrates: une norme aux pieds d'argile. La recherche, 339, 31-34.

Baumgartner, F. R., \& Jones, B. D. (2002). Policy Dynamics. Chicago, IL : University of Chicago Press.

Benford, R. D. (1997). An Insider's Critique of the Social Movement Framing Perspective. Sociological Inquiry, 67 (4), 409-430.

Benford, R. D., \& Snow, D. A. (2000). Framing Processes and Social Movements. An Overview and Assessment. Annual Review of Sociology, 26 (2), 611-639.

Bodiguel, M. (1996). La qualité des eaux dans l'Union Européenne. Pratique d'une réglementation commune. Paris : L'Harmattan.

Boltanski, L., Darré, Y., \& Schiltz, M.-A. (1984). La dénonciation, Actes de la recherche en sciences sociales, 51 (1), 3-40.

Bourblanc, M. \& Brives, H. (2009). La construction du caractère 'diffus' des pollutions agricoles. Etudes rurales, 183 (1), 161-176.

Bourblanc, M. (2011). Emancipated instruments. Dependence on instruments in the management of agricultural water pollution in the Côtes-d'Armor department (19902007). Revue française de science politique (English), 61 (6), 25-45.

Cobb, R., \& Elder, C. D. (1983). Participation in American Politics. The Dynamics of Agenda Building, Baltimore, MA : John Hopkins University Press.

Cobb, R. W., \& Elder, M. H. (1997). Cultural Strategies of Agenda Denial. Lawrence, KS: University of Kansas Press.

Contamin, J.-G. (2010). Cadrages et luttes de sens. In O.Filieule, E.Agrikoliansky, \& I.Sommier (eds.), Penser les mouvements sociaux. Conflits sociaux et contestations dans les sociétés contemporaines (pp. 55-75). Paris : La Découverte. 
Edelman, M. J. (1964). The Symbolic Uses of Politics. Chicago: IL: University of Illinois Press.

Gilbert, C. \& Henry, E. (2009). Comment se construisent les problèmes de santé publique. Paris : La Découverte.

Goodwin, J., \& Jasper, J. M. (1999). Caught in a Winding, Snarling Vine: the Structural Bias of Political Process Theory. Sociological Forum, 14 (1), 27-54.

Gusfield, J. R. (1980). The Culture of Public Problems. Drinking-Driving and the Symbolic Order. Chicago, ILL: The University of Chicago Press.

Hassenteufel, P. (2008). Sociologie politique; l'action publique. Paris: Armand Colin.

Jenkins-Smith, H., \& Sabatier, P. (1994). "Evaluating the Advocacy Coalition Framework," Journal of Public Policy 14, 175-203.

Kernalegenn, T. (2004). Bretagne et écologie. Approche culturelle d'une dynamique identitaire. In N. Dugalès, R. Le Coadic, \& F. Patez (eds.), Et la Bretagne? Héritage, identités, projets. Rennes (Bretagne): PUR.

Kingdon, J. W. (1984). Agendas, Alternatives and Public Policies. Boston: Little Brown.

Kitsuse, J. I., \& Spector, M. (1973). Toward a Sociology of Social Problems: Social Conditions, Value-Judgements and Social Problems. Social Problems, 20 (4), 407419.

L'Hirondel, J.-L. (2004). Santé et Environnement : Le cas des nitrates. Toxiques, inoffensifs ou bénéfiques. Actes des assises internationales Envirobio, Liffré (Bretagne): Editions de l'Institut scientifique et technique de l'environnement (2nd edition).

Le Bourdonnec, Y. (1996). Le miracle économique breton. Paris: Calmann-Lévy.

Lascoumes,P., \& Le Galès, P. (2004). Gouverner par les instruments. Paris : Presses de SciencesPo.

McCarthy, J. D. and Zald, M. N. (1977). Resource Mobilization and Social Movements: a Partial Theory. American Journal of Sociology, 82 (6), 1212-1241.

McAdam, D,, McCarthy, J. D., \& Zald, M. N. (1996). Comparative Perspectives on Social Movements. Political Opportunities, Mobilizing Structures and Cultural Framings. Cambridge, Mass : Cambridge University Press.

Mettoux, A.-P. (2002). Associations et changement social, (Unpublished doctoral dissertation). Université Paris 10, France.

Morris, A. D. (2004). Reflections on Social Movement Theory: Criticisms and Proposals. In J. Goodwin \& J. Jasper (eds.), Rethinking Social Movements: Structure, Meaning, and Emotion (pp. 233-46). Lanham, MD: Rowman and Littlefield Publishers.

Neveu, E. (1996). Sociologie des mouvements sociaux. Paris: La Découverte.

Oberschall, A. R. (1973). Social Conflicts and Social Movements. Englewood Cliffs, NJ: Prentice-Hall Inc.

Padioleau, J.-G. (1982). L'Etat au concret, Paris : PUF.

Rochefort, D. A., \& Cobb, R. W. (1994). The Politics of Problem Definition. Shaping the Policy Agenda. Lawrence, KS: University Press of Kansas. 
Snow, D. A., Burke Rochford, E., Worden, S.K., \& Benford, R.D. (1986). Frame Alignment Processes, Micromobilization, and Movement Participation. American Sociological Review, 51 (4), 464-81.

Steinberg, M. W. (1999). The Talk and Back Talk of Collective Action: a Dialogic Analysis of Repertoires of Discourse among Nineteenth-Century English Cotton Spinners, American Journal of Sociology, 105, 736-780.

Stone, D. A. (1989). Causal Stories and the Formation of Policy Agendas. Political Science Quarterly, 104 (2), 281-300.

Thoenig, J-C. (1998). Politiques publiques et action publique. Revue internationale de politique comparée, 5 (2), 295-314.

Vlassopoulou, C. , \& Larrue, C. (1999). Changing Definitions and Networks in Clean Air Policy in France. In W. Grant, P. Knoepfel \& A. Perl (eds.), The Politics of Improving Urban Air Quality. (pp. 93-106). Bodmin: MPG Books Ltd.

Yearley, S. (1991). The Green Case. A Sociology of Environmental Issues, Arguments and Politics. London: Harper Collins Publishers. 